\title{
A Simple Method of Preparation of High Silica Zeolite Y and Its Performance in the Catalytic Cracking of Cumene
}

\author{
Zhanjun Liu, Chenxi Shi, Dan Wu, Shixuan He, and Bo Ren \\ School of Pharmacy, North China University of Science and Technology, Tangshan 063000, China \\ Correspondence should be addressed to Bo Ren; renbo041219@163.com
}

Received 24 February 2016; Revised 17 May 2016; Accepted 9 June 2016

Academic Editor: Sanjay Behura

Copyright (C) 2016 Zhanjun Liu et al. This is an open access article distributed under the Creative Commons Attribution License, which permits unrestricted use, distribution, and reproduction in any medium, provided the original work is properly cited.

\begin{abstract}
A series of high silicon zeolites Y were prepared through direct synthetic method by using silica sol as the silicon source and sodium aluminate as the aluminum source. The effects of alkalinity and crystallization time of the process of synthesis were investigated. To separately reveal the crystalline structure, element content, morphology, and surface areas, the as-synthesized zeolite Y was characterized by powder X-ray diffraction (XRD), X-ray fluorescence (XRF), scanning electron microscopy (SEM), and $\mathrm{N}_{2}$ adsorption-desorption isotherms (BET). The results show the as-synthesized zeolite $\mathrm{Y}$ with high relative crystallization and uniform morphology; the $\mathrm{SiO}_{2} / \mathrm{Al}_{2} \mathrm{O}_{3}$ ratio was about 4.54 6.46. For an application, the zeolite cracking activity was studied with cumene as the probe molecules.
\end{abstract}

\section{Introduction}

Zeolites are an important class of crystalline aluminosilicates materials with open-framework structures, and they have been widely used as separations, ion exchange, and acidic catalysts for size and shape selective catalytic reactions by molecular-sized microporosity [1-3]. The synthetic zeolites microporous crystalline solids have been produced in number of industrial scale processes for many years, and the zeolite $\mathrm{Y}$ is highly versatile molecular sieve from the Faujasite family with the three-dimensional pore structure and the pore diameter is about $0.74 \mathrm{~nm}[4,5]$. Although many other porous materials have emerged, the zeolite $\mathrm{Y}$ continues to keep the most popular pyrolysis catalyst in the international field because of the inherent surface acidity and good hydrothermal stability.

Faujasite zeolites are commonly separated into two classes: (1) zeolite $\mathrm{X}$, which has a silicon to aluminum $\mathrm{Si} / \mathrm{Al}$ ratio between 1 and 1.5 , and (2) zeolite $\mathrm{Y}$ which has a silicon to aluminum $\mathrm{Si} / \mathrm{Al}$ ratio above 1.5 . The large pore openings and large cavities of zeolite $\mathrm{X}$ make it an attractive material for ion exchange, adsorption, and drying processes $[6,7]$. Notably, the thermal and hydrothermal stabilities of zeolite $\mathrm{Y}$ are strongly related to its $\mathrm{Si} / \mathrm{Al}$ ratio, which plays a very important role in materials intended for application as fluidized catalytic cracking (FCC) catalysts.

However, conventional zeolite Y ( $\mathrm{Si} / \mathrm{Al}$ molar ratio below 2.5) application to petrochemical industry is limited due to the weak acidity, as well as poor hydrothermal stability. For the sake of better industrial realm application, conventional $\mathrm{Y}$ zeolite is replaced by a high silica ultrastable $\mathrm{Y}$ zeolite (USY, with $\mathrm{Si} / \mathrm{Al}>4$ ) [8], prepared from various posttreatments which include steaming at elevated temperatures [9, 10], introduction of $\mathrm{SiCl}_{4}$ vapor at moderate temperatures [11], treatment with ammonium hexafluorosilicate [12], and chelating agents [13]. Unfortunately, these posttreatments methods require several posttreatments and heat treatment often leads to structure being distorted.

Compared with these posttreatments, the direct synthesis method is a more convenient way to obtain the high silica $\mathrm{Y}$ zeolite. The direct synthesis method includes structuredirecting agent (SDA) method [14, 15]; organic templates method, for example, tetramethylammonium cation $\left(\mathrm{TMA}^{+}\right)$ from tetramethylammonium bromide (TMABr), or tetramethylammonium hydroxide (TMAOH), is the most typical organic template [16-20]; crown ether family [21,22] and $\mathrm{N}$-methylpyridinium iodide [5] are also occasionally used. However, the SDA has instability and bad repeatability, which 
limit its application in industry [15] and the organic templates method needs to consume a large amount of organic template in the synthesis process, and the high-cost and toxicity limit the broader applications in industry. Hence it is very desirable to find a low-cost approach for the synthesis of high silica zeolite $\mathrm{Y}$.

In the present work, we reduce the basicity of the synthesis system by adding sulfuric acid to improve the $\mathrm{SiO}_{2} / \mathrm{Al}_{2} \mathrm{O}_{3}$ ratio, and the effect of alkalinity and crystallization time is investigated to obtain a reasonable basicity. Under this basicity, we synthesized high silica zeolite $\mathrm{Y}$ without structure-directing agent or organic template and the crystallization time is also acceptable. Different samples are applied as a catalyst for catalytic cracking of cumene to clarify the effect of the $\mathrm{SiO}_{2} / \mathrm{Al}_{2} \mathrm{O}_{3}$ ratio on the catalytic performance, and, encouragingly, it demonstrates a strong potential in petroleum processing.

\section{Experimental Details}

2.1. Chemicals. All the chemicals were directly used as received with no further purification. The reactants used were aqueous colloidal silica $\left(w\left(\mathrm{SiO}_{2}\right)=30 \%\right.$, Sinopharm Chemical Reagent Co., Ltd.), sodium aluminate $\left(w\left(\mathrm{Al}_{2} \mathrm{O}_{3}\right)\right.$ $>45 \%$, Sinopharm Chemical Reagent Co., Ltd.), sodium hydroxide $(w(\mathrm{NaOH})>96 \%$, Sinopharm Chemical Reagent Co., Ltd. $)$, sulfuric acid $\left(w\left(\mathrm{H}_{2} \mathrm{SO}_{4}\right)>98 \%\right.$, Sinopharm Chemical Reagent Co., Ltd.), and deionized water.

2.2. Preparation of Zeolite $Y$. Sodium aluminate, sodium hydroxide, and deionized water were placed in a beaker to ensure good mixing on a magnetic stirrer at room temperature. After the solution became transparent, the aqueous colloidal silica was added under agitation for $2 \mathrm{~h}$ to yield the sodium aluminate solution. At last, the sulfuric acid was added to the gel to produce a gel with the overall stoichiometry $\mathrm{Na}_{2} \mathrm{O}: \mathrm{Al}_{2} \mathrm{O}_{3}: \mathrm{SiO}_{2}: \mathrm{H}_{2} \mathrm{O}: \mathrm{H}_{2} \mathrm{SO}_{4}$ $=4.3: 1: 10: 180: a$ (where $a=0 ; 0.67 ; 1.34 ; 2.01$ ). This gel was homogenized, and then it was transferred to a stainless-steel autoclave (50 $\mathrm{mL}$ PTFE lined); then the sealed autoclave was placed in the oven at $100^{\circ} \mathrm{C}$ for hours. After this procedure, the products were filtered, washed with deionized water, and dried. The as-synthesized zeolite Y was denoted as NaY- $a-b$.

2.3. Preparation of H-Type Zeolite Y. The sodium form of zeolite was converted to the hydrogen form by ammonium ion exchange method. The zeolite was treated with $1 \mathrm{M}$ ammonium chloride solution at $80^{\circ} \mathrm{C}$ for $2 \mathrm{~h}$. Note that the zeolite to ammonium chloride solution was $1 \mathrm{~g}: 100 \mathrm{~mL}$. The residue was filtered and washed with distilled water; then the sample was dried at a temperature of $120^{\circ} \mathrm{C}$ for $4 \mathrm{~h}$. The above cycle was repeated three times to get complete exchange of sodium. As a final step, the samples were heated at $550^{\circ} \mathrm{C}$ for $5 \mathrm{~h}$ to decompose to $\mathrm{H}$-type zeolite. The zeolite $\mathrm{HY}$ was denoted as HY- $a-b$ ( $a$ and $b$ have the same meaning as those in Section 2.2).

2.4. H-Type Zeolite Y Activity Evaluation. The zeolite cracking activity was determined with cumene as the probe

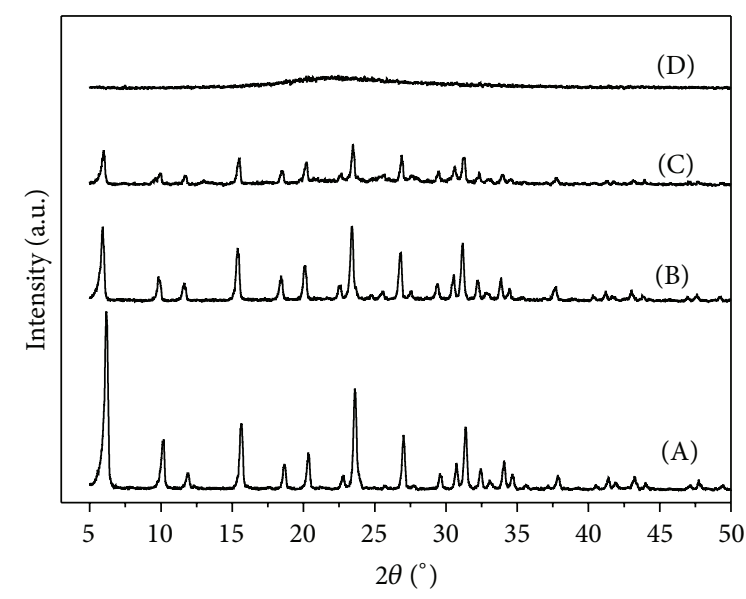

FIGURE 1: XRD patterns for $\mathrm{NaY}$ zeolite samples with different $\mathrm{H}_{2} \mathrm{SO}_{4} / \mathrm{Al}_{2} \mathrm{O}_{3}$ and different crystallization time. (A) NaY-0-12, (B) NaY-0.67-48, (C) NaY-1.34-312, and (D) NaY-2.01-720.

molecules, which used a flow-type apparatus equipped with a fixed-bed reactor. Nitrogen was used as carrier gas at flows of $3.0 \mathrm{~L} / \mathrm{h}$. The catalysts were pressed binder-free and crushed to a particle size of 60-80 meshes, and the catalyst amount was $0.26 \mathrm{~g}$. In the case of cumene cracking, nitrogen saturated with vaporized cumene at $300^{\circ} \mathrm{C}$ was passed through the reactor (the flow rate of liquid state cumene $=6.0 \mathrm{~mL} / \mathrm{h}$ ), and the reaction temperature was $300^{\circ} \mathrm{C}$ as well. Reaction products were analyzed by an online gas chromatograph with flame ionization detector.

2.5. Sample Characterization. The powder XRD patterns were collected on the XD-3 of the Beijing Purkinje General Instrument Co., with graphite monochromatized $\mathrm{Cu}-\mathrm{K} \alpha(\lambda$ $=0.154056 \mathrm{~nm}$ ) radiation at $36 \mathrm{kV}, 20 \mathrm{~mA}$. All the samples were collected in the range of $5-50^{\circ}$ with continuous scanning mode, and the scanning speed was set to be $2 \% \mathrm{~min}$. The scanning electron microscopy (SEM) images were captured on a Hitachi field-emission scanning electron microscope (S4800 ) operated at an accelerating voltage of $15 \mathrm{kV}$. Elemental compositions of the samples were carried out on a Philips Magix (PW2403) X-ray fluorescence (XRF) spectrometer. The data were analyzed using an IQ + fast quantitative software package. $\mathrm{N}_{2}$ adsorption-desorption was performed at $77 \mathrm{~K}$ in the Bei Shi De Instrument Technology (Beijing) Co., Ltd. (3H-2000PS1), and the samples were degassed at $250^{\circ} \mathrm{C}$ for $6 \mathrm{~h}$ prior to analysis.

\section{Results and Discussion}

3.1. Zeolite Y Crystallization with Different Alkalinity. The XRD patterns with different $\mathrm{H}_{2} \mathrm{SO}_{4} / \mathrm{Al}_{2} \mathrm{O}_{3}$ and different crystallization time are shown in Figure 1. Samples (A), (B), and $(\mathrm{C})$ exhibited the typical diffraction peaks of zeolite $\mathrm{Y}$ [23], the XRD patterns correspond to gel evolution from the initial amorphous precursors (NaY-0-4), and the other XRD data can be found in detail in the supplementary information Figure S1 (see Supplementary Material available 


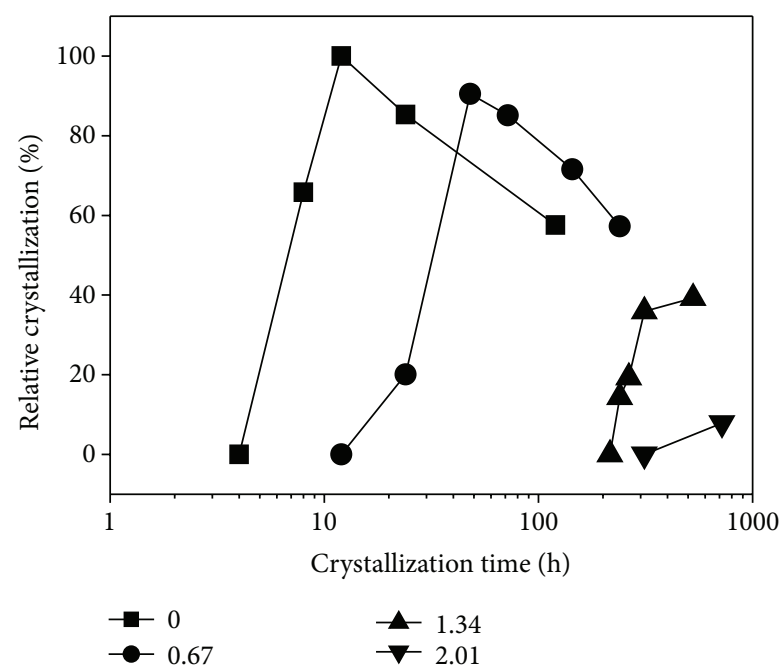

FIGURE 2: The relation of relative crystallinity and crystallization time with different $\mathrm{H}_{2} \mathrm{SO}_{4} / \mathrm{Al}_{2} \mathrm{O}_{3}$.

online at http://dx.doi.org/10.1155/2016/1486107). After $8 \mathrm{~h}$ (NaY-0-8) of crystallization XRD peaks corresponding to the Y-type zeolite structure emerged; afterward at 8-12 h of crystallization the XRD peaks become more apparent, which indicates a progressive growth of the crystallites until $12 \mathrm{~h}$. Figure $1(\mathrm{~B})$ shows XRD peaks corresponding to the FAUtype zeolite structure emerged after $48 \mathrm{~h}$. According to the demonstrations, the alkalinity of the synthesis system directly affects the crystallization time. The crystallization time of a high crystalline zeolite $\mathrm{Y}$ increased from $8 \mathrm{~h}$ to $48 \mathrm{~h}$ when the $\mathrm{H}_{2} \mathrm{SO}_{4} / \mathrm{Al}_{2} \mathrm{O}_{3}$ changed from 0 to 0.67 , and it extends to $312 \mathrm{~h}$ when $\mathrm{H}_{2} \mathrm{SO}_{4} / \mathrm{Al}_{2} \mathrm{O}_{3}=1.34$ (Figure $1(\mathrm{C})$ ). At last, when $\mathrm{H}_{2} \mathrm{SO}_{4} / \mathrm{Al}_{2} \mathrm{O}_{3}=2.01$ (Figure $1(\mathrm{D})$ ), the transformation process from the initial amorphous precursors to zeolite could not emerge.

Figure 2 shows the relation of relative crystallinity and crystallization time with different $\mathrm{H}_{2} \mathrm{SO}_{4} / \mathrm{Al}_{2} \mathrm{O}_{3}$. In order to calculate relative crystallinity of the samples, a modified procedure described in [24] was used. After a background correction, the peak intensity sum of (111) $(2 \theta=6.2)$, (331) $(2 \theta=15.6)$, and (533) $(2 \theta=22.1)$ is an evaluation criterion; the maximum peak intensity (sample NaY-0-24) is designated as $100 \%$. Figure 2 reflects the relations between the alkalinity of the synthesis system and the crystallization times. In this study, the sulfuric acid works as an additive to reduce the basicity of the synthesis system and the solubility of the aluminosilicate, which led to the decreased crystallization rate.

3.2. XRF. The detailed $\mathrm{SiO}_{2} / \mathrm{Al}_{2} \mathrm{O}_{3}$ ratio data are listed in Table 1 . It reveals that the alkalinity of the synthesis system has important impacts on $\mathrm{SiO}_{2} / \mathrm{Al}_{2} \mathrm{O}_{3}$ ratio of zeolite $\mathrm{NaY}$. The $\mathrm{SiO}_{2} / \mathrm{Al}_{2} \mathrm{O}_{3}$ ratio of samples increases from 4.54 to 6.45 with the $\mathrm{H}_{2} \mathrm{SO}_{4} / \mathrm{Al}_{2} \mathrm{O}_{3}$ in the gel changing from 0 to 1.34 .

3.3. SEM. SEM images of the samples collected at different $\mathrm{H}_{2} \mathrm{SO}_{4} / \mathrm{Al}_{2} \mathrm{O}_{3}$ and different crystallization time are presented in Figure 3. Sample (a) showed relatively uniform spherical
TABLE 1: The element content and $\mathrm{SiO}_{2} / \mathrm{Al}_{2} \mathrm{O}_{3}$ measured by XRF.

\begin{tabular}{lcccc}
\hline Sample & $\begin{array}{c}\mathrm{SiO}_{2} \\
(w \%)\end{array}$ & $\begin{array}{c}\mathrm{Al}_{2} \mathrm{O}_{3} \\
(w \%)\end{array}$ & $\begin{array}{c}\mathrm{Na}_{2} \mathrm{O} \\
(w \%)\end{array}$ & $\begin{array}{c}\mathrm{SiO}_{2} / \mathrm{Al}_{2} \mathrm{O}_{3} \\
(n / n)\end{array}$ \\
\hline $\mathrm{NaY}-0-12$ & 62.8 & 23.5 & 13.5 & 4.54 \\
$\mathrm{NaY}-0.67-48$ & 66.2 & 21.4 & 12.3 & 5.26 \\
$\mathrm{NaY}-0.67-144$ & 66.1 & 21.4 & 12.3 & 5.25 \\
$\mathrm{NaY}-1.34-312$ & 70.3 & 18.5 & 10.9 & 6.46 \\
\hline
\end{tabular}

particles in the size range of $0.8-1.0 \mu \mathrm{m}$. Under the lower alkalinity of the synthesis system, the particles size of sample (c) increased to $1.5 \mu \mathrm{m}$, and sample (e) particles size was about $4.0 \mu \mathrm{m}$; this law of variation about particle size has been reported in the literature [25]. It is worth mentioning that these particles' surface was rough and angular; the characteristics of morphologies facilitated differentiating the crystal and the amorphous.

3.4. BET. Figure 4 shows the $\mathrm{N}_{2}$ adsorption-desorption isotherms of the samples obtained at different alkalinity of gel, and the detailed data are in Table 2. All the samples exhibited a sharp uptake of $\mathrm{N}_{2}$ at very low relative pressures $\left(P / P_{0}<0.001\right)$, implying the presence of micropores. On the other hand, samples (A) and (B) exhibited another uptake appeared at high relative pressure $\left(0.85<P / P_{0}<1.0\right)$, which originated from intraparticle macropores [23] because of the uneven grain sizes of sample (C) (Figure 3(e)); it could not form intraparticle macropores. Particularly, sample (A) presented higher $\mathrm{N}_{2}$ adsorption capacity (about $240 \mathrm{~cm}^{3} / \mathrm{g}$ ) at low pressures than sample (B) (about $220 \mathrm{~cm}^{3} / \mathrm{g}$ ) and sample (C) (about $100 \mathrm{~cm}^{3} / \mathrm{g}$ ), suggesting that the zeolite $\mathrm{NaY}$ synthesized in $\mathrm{H}_{2} \mathrm{SO}_{4} / \mathrm{Al}_{2} \mathrm{O}_{3}=0$ had larger surface area than other alkalinity. As shown in Table 2, the micropore surface area was decreased from $944.1 \mathrm{~m}^{2} / \mathrm{g}$ for sample (A), to $845.6 \mathrm{~m}^{2} / \mathrm{g}$ for sample (B), to $357.8 \mathrm{~m}^{2} / \mathrm{g}$ for sample (C). The micropore volume revealed the same decline tendencies in the following order: sample $(\mathrm{C})<$ sample $(\mathrm{B})<$ sample (A). Based on the above results, our study suggests that the textural parameters are related to the crystallinity of the samples, when the $\mathrm{H}_{2} \mathrm{SO}_{4} / \mathrm{Al}_{2} \mathrm{O}_{3}=1.34$; the product had low degree of crystallization and BET surface area.

The XRD patterns of the samples transformed into H-type zeolite are illustrated in Figure 5. Following ion exchange and calcinations, the XRD features of sample (A) weaken obviously except for (111) peak, but the positions of (111), (331), and (533) peaks change, indicating the part of the HY structure collapsed, whereas samples (B), (C), (D), and (E) show only a diminution of the original XRD intensity, but the peaks positions do not change clearly. The temperature of $\mathrm{NH}_{4} \mathrm{Y}$ structural collapse is strongly associated with the ammonium ion exchange degree and the $\mathrm{SiO}_{2} / \mathrm{Al}_{2} \mathrm{O}_{3}$ molar ratio. Hence the partial collapse of sample (A) should be the result from the low $\mathrm{SiO}_{2} / \mathrm{Al}_{2} \mathrm{O}_{3}$. Because the temperature of structural collapse was lower than the ammonia decomposition, $\mathrm{NH}_{4} \mathrm{X}$ and the low silica $\mathrm{NH}_{4} \mathrm{Y}$ zeolite could not be transformed to $\mathrm{H}$-form zeolite by calcination method. 
TABLE 2: Textural parameters of the samples obtained at different $\mathrm{H}_{2} \mathrm{SO}_{4} / \mathrm{Al}_{2} \mathrm{O}_{3}$.

\begin{tabular}{|c|c|c|c|c|}
\hline Sample & Relative crystallinity \% & BET surface area $\left[\mathrm{m}^{2} \mathrm{~g}^{-1}\right]$ & Micropore surface area $\left[\mathrm{m}^{2} \mathrm{~g}^{-1}\right]$ & Micropore volume $\left[\mathrm{cm}^{3} \mathrm{~g}^{-1}\right]$ \\
\hline (A) $\quad \mathrm{NaY}-0-12$ & 100 & 986.6 & 944.1 & 0.37 \\
\hline (B) NaY-0.67-48 & 91 & 911.4 & 845.6 & 0.33 \\
\hline (C) NaY-1.34-312 & 36 & 401.8 & 357.8 & 0.14 \\
\hline
\end{tabular}

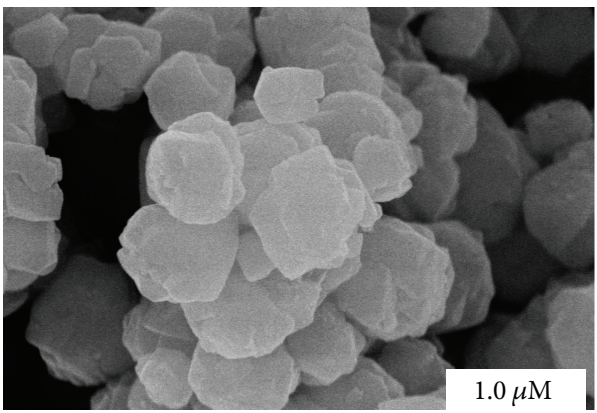

(a)

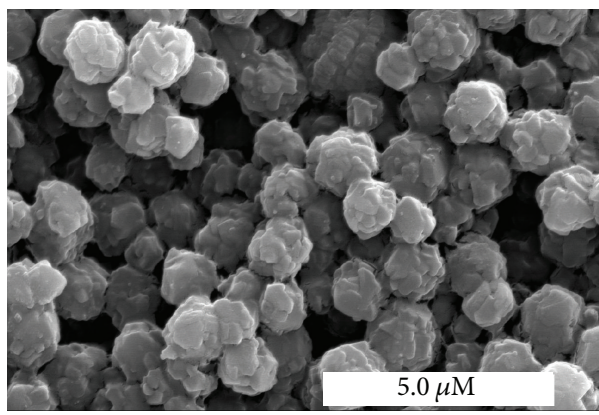

(c)

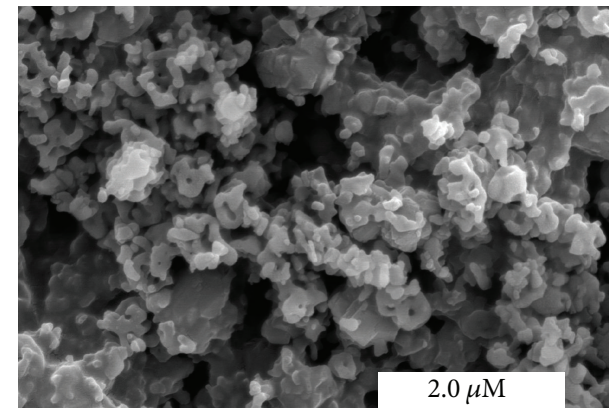

(b)

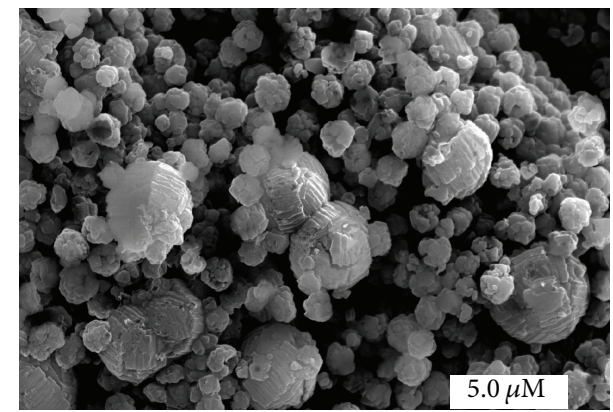

(d)

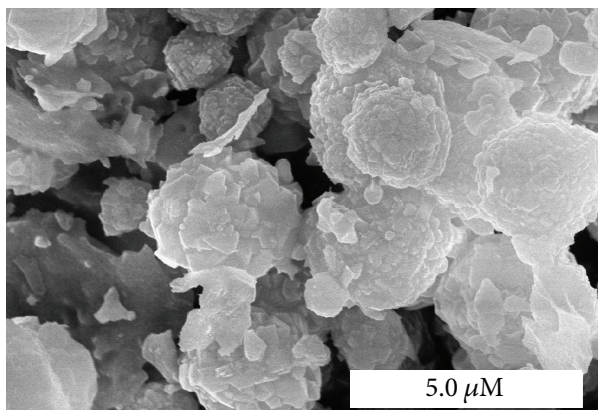

(e)

FIGURE 3: The SEM images of the samples with different $\mathrm{H}_{2} \mathrm{SO}_{4} / \mathrm{Al}_{2} \mathrm{O}_{3}$ and different crystallization time. (a) NaY-0-12; (b) NaY-0.67-24; (c) NaY-0.67-48; (d) NaY-0.67-144; (e) NaY-1.34-312.

3.5. Catalytic Cracking of Cumene. The catalytic activity of the samples is shown in Figure 6. The sample HY-0-12 had the lowest activity, the conversion of decomposition was only $12.7 \%$, and the catalytic activity disappeared when the reaction lasted for about $70 \mathrm{~min}$. It should be caused by the low content of zeolite; the sample HY-0-12 was mainly composed of amorphous silica-alumina material. However, samples HY-0.67-48, HY-0.67-72, and HY-0.67-144 had better performance; in particular the conversion of HY-0.67-48 could reach as high as $88.3 \%$ at the beginning of the reaction and $20.0 \%$ when the reaction lasted for about $390 \mathrm{~min}$; the conversions of HY-0.67-72 and HY-0.67-144 were slightly lower than HY-0.67-48, 72\% and 75\%, respectively. The catalytic activity is related to the relative crystallinity, under the same $\mathrm{SiO}_{2} / \mathrm{Al}_{2} \mathrm{O}_{3}$ ratio condition; the higher the relative crystallinity, the higher the catalytic activity.

In addition, we found the activity reduces with the increasing reaction time. This is mainly caused by the coke deposit on catalysts; the coke deposition can block the zeolite pores and prevent active sites contact with cumene. 


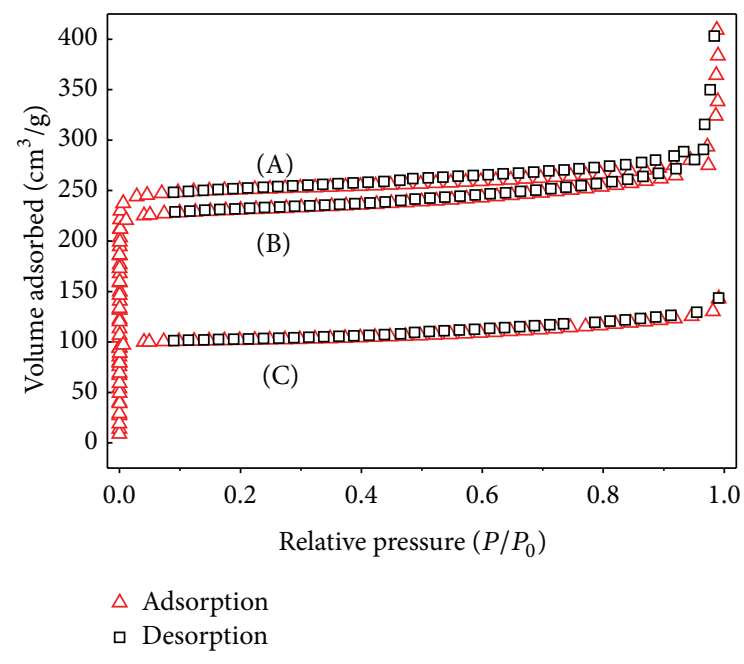

FIGURE 4: $\mathrm{N}_{2}$ adsorption-desorption isotherms of the samples obtained at different $\mathrm{H}_{2} \mathrm{SO}_{4} / \mathrm{Al}_{2} \mathrm{O}_{3}$. (A) NaY-0-12; (B) NaY-0.67-48; (C) NaY-1.34-312.

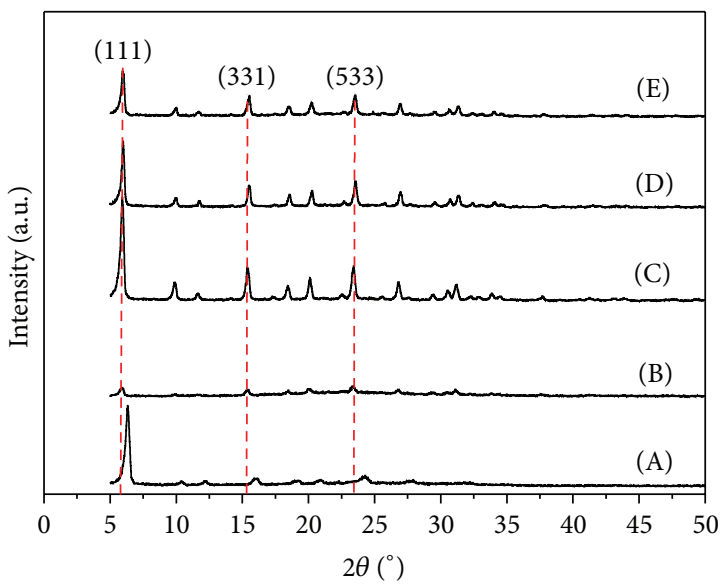

FIGURE 5: XRD patterns of the H-type zeolite samples. (A) HY-0-12; (B) HY-0.67-24; (C) HY-0.67-48; (D) HY-0.67-144; (E) HY-1.34-312.

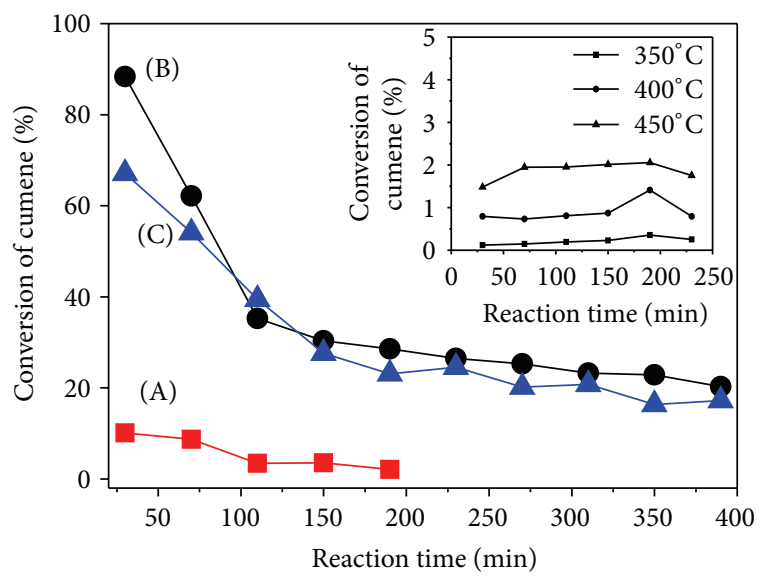

FIGURE 6: The cumene catalytic reaction performance of the samples and the thermal cracking without catalyst (insert). (A) HY-0-12, (B) HY-0.67-48, and (C) HY-1.34-312.

\section{Conclusions}

We have demonstrated that high silica Y zeolite can be synthesized using direct synthesis method without adding any organic additive or SDA. The relative crystallinity and crystallization time of zeolite $\mathrm{NaY}$ particles can be controlled by the $\mathrm{H}_{2} \mathrm{SO}_{4} / \mathrm{Al}_{2} \mathrm{O}_{3}$ ratio of the synthesis gel. The crystallization time was also acceptable when the synthesis gel $\mathrm{Na}_{2} \mathrm{O}: \mathrm{Al}_{2} \mathrm{O}_{3}: \mathrm{SiO}_{2}: \mathrm{H}_{2} \mathrm{O}: \mathrm{H}_{2} \mathrm{SO}_{4}=4.3: 1: 10: 180: 0.67$. $\mathrm{XRD}$ and XRF show that the zeolite $\mathrm{Y}$ nanocrystals obtained are highly crystalline and high $\mathrm{SiO}_{2} / \mathrm{Al}_{2} \mathrm{O}_{3}$ ratio. The assynthesized zeolite $\mathrm{Y}$ nanocrystals show high $\mathrm{N}_{2}$ adsorption and BET surface area and micropore volume are determined to be $911.4 \mathrm{~m}^{2} / \mathrm{g}$ and $0.33 \mathrm{~cm}^{3} / \mathrm{g}$, respectively. In addition, compared with lower silica Y zeolite, the as-synthesized high silica Y zeolite shows excellent cracking performance.

\section{Competing Interests}

The authors declare that they have no competing interests.

\section{Acknowledgments}

The research was supported by the project supported by Hebei Provincial Natural Science Foundation of China, Shijiazhuang Pharmaceutical Group (CSPC) Foundation (H2013209192), and the Funding Project for University Students' Innovation and Venture Education of the North China University of Science and Technology (X2015063).

\section{References}

[1] B. Ren, S. Y. Bai, J. H. Sun, F. Zhang, and M. Fan, "Controllable synthesis of obvious core-shell structured Y/Beta composite zeolite by a stepwise-induced method," RSC Advances, vol. 4, no. 43, pp. 22755-22758, 2014.

[2] K. Cho, K. Na, J. Kim, O. Terasaki, and R. Ryoo, "Zeolite synthesis using hierarchical structure-directing surfactants: retaining porous structure of initial synthesis gel and precursors," Chemistry of Materials, vol. 24, no. 14, pp. 2733-2738, 2012.

[3] M. Maldonado, M. D. Oleksiak, S. Chinta, and J. D. Rimer, "Controlling crystal polymorphism in organic-free synthesis of Na-Zeolites," Journal of the American Chemical Society, vol. 135, no. 7, pp. 2641-2652, 2013.

[4] D. Karami and S. Rohani, "A novel approach for the synthesis of zeolite Y," Industrial \& Engineering Chemistry Research, vol. 48, no. 10, pp. 4837-4843, 2009.

[5] L. F. Zhu, L. M. Ren, S. J. Zeng et al., "High temperature synthesis of high silica zeolite $y$ with good crystallinity in the presence of N-methylpyridinium iodide," Chemical Communications, vol. 49, no. 89, pp. 10495-10497, 2013.

[6] A. M. Yusof, N. A. Nizam, and N. A. A. Rashid, "Hydrothermal conversion of rice husk ash to faujasite-types and NaA-type of zeolites," Journal of Porous Materials, vol. 17, no. 1, pp. 39-47, 2010.

[7] T. Frising and P. Leflaive, "Extraframework cation distributions in X and Y faujasite zeolites: a review," Microporous and Mesoporous Materials, vol. 114, no. 1-3, pp. 27-63, 2008. 
[8] T. J. Daou, M. Boltz, L. Tzanis, L. Michelin, and B. Louis, "Gas-phase chlorination of aromatics over FAU- and EMT-type zeolites," Catalysis Communications, vol. 39, pp. 10-13, 2013.

[9] Q. L. Wang, G. Giannetto, M. Torrealba, G. Perot, C. Kappenstein, and M. Guisnet, "Dealumination of zeolites II. Kinetic study of the dealumination by hydrothermal treatment of a NH4NaY zeolite," Journal of Catalysis, vol. 130, no. 2, pp. 459470, 1991.

[10] C. S. Triantafillidis, A. G. Vlessidis, and N. P. Evmiridis, "Dealuminated H-Y zeolites: influence of the degree and the type of dealumination method on the structural and acidic characteristics of H-Y zeolites," Industrial \& Engineering Chemistry Research, vol. 39, no. 2, pp. 307-319, 2000.

[11] L. Kubelkova, V. Seidl, J. Novakova, S. Bednarova, and P. Jiru, "Properties of Y-type Zeolites with various silicon/aluminium ratios obtained by dealumination with silicon tetrachloride," Journal of the Chemical Society Faraday Transactions, vol. 80, no. 6, pp. 1367-1376, 1984.

[12] M. Neuber, V. Dondur, H. G. Karge, L. Pacheco, S. Ernst, and J. Weitkamp, "Spectroscopic and catalytic characterization of Faujasites dealuminated via the $\left(\mathrm{NH}_{4}\right)_{2} \mathrm{SiF}_{6}$ method," Studies in Surface Science \& Catalysis, vol. 37, pp. 461-469, 1988.

[13] G. T. Kerr, "Chemistry of crystalline aluminosilicates. V. preparation of aluminium-deficient Faujasites," Journal of Physical Chemistry, vol. 72, no. 7, pp. 2594-2596, 2002.

[14] Y. Zhao, Z. Liu, W. Li et al., "Synthesis, characterization, and catalytic performance of high-silica Y zeolites with different crystallite size," Microporous and Mesoporous Materials, vol. 167, no. 1-3, pp. 102-108, 2013.

[15] B. Ren, J. H. Sun, Y. Liu, L. Zhang, and H. Zhou, "Rapid synthesis of nanosized NaY zeolite by hydrothermal method," Acta Petrolei Sinica (Petroleum Processing Section), vol. 28, no. 1, pp. 7-12, 2012.

[16] B. A. Holmberg, H. T. Wang, J. M. Norbeck, and Y. S. Yan, "Controlling size and yield of zeolite $\mathrm{Y}$ nanocrystals using tetramethylammonium bromide," Microporous and Mesoporous Materials, vol. 59, no. 1, pp. 13-28, 2003.

[17] G. S. Zhu, S. L. Qiu, J. H. Yu et al., "Synthesis and characterization of high-quality Zeolite LTA and FAU single nanocrystals," Chemistry of Materials, vol. 10, no. 6, pp. 1483-1486, 1998.

[18] N. Taufiqurrahmi, A. R. Mohamed, and S. Bhatia, "Nanocrystalline zeolite beta and zeolite Y as catalysts in used palm oil cracking for the production of biofuel," Journal of Nanoparticle Research, vol. 13, no. 8, pp. 3177-3189, 2011.

[19] O. Larlus, S. Mintova, and T. Bein, "Environmental syntheses of nanosized zeolites with high yield and monomodal particle size distribution," Microporous and Mesoporous Materials, vol. 96, no. 1-3, pp. 405-412, 2006.

[20] B. A. Holmberg, H. Wang, and Y. Yan, "High silica zeolite Y nanocrystals by dealumination and direct synthesis," Microporous and Mesoporous Materials, vol. 74, no. 1-3, pp. 189-198, 2004.

[21] T. J. Daou, J. Dhainaut, A. Chappaz et al., "The use of original structure-directing agents for the synthesis of EMC-1 zeolite," Oil \& Gas Science and Technology, vol. 70, no. 3, pp. 447-457, 2015.

[22] D. H. Yuan, D. W. He, S. T. Xu et al., "Imidazolium-based ionic liquids as novel organic SDA to synthesize high-silica Y zeolite," Microporous and Mesoporous Materials, vol. 204, pp. 1-7, 2015.

[23] Y. Huang, K. Wang, D. H. Dong et al., "Synthesis of hierarchical porous zeolite NaY particles with controllable particle sizes,"
Microporous and Mesoporous Materials, vol. 127, no. 3, pp. 167175, 2010.

[24] A. Petushkov, J. Freeman, and S. C. Larsen, "Framework stability of nanocrystalline $\mathrm{NaY}$ in aqueous solution at varying $\mathrm{pH}$," Langmuir, vol. 26, no. 9, pp. 6695-6701, 2010.

[25] T. F. Chaves, H. O. Pastore, and D. Cardoso, "A simple synthesis procedure to prepare nanosized faujasite crystals," Microporous and Mesoporous Materials, vol. 161, no. 5, pp. 67-75, 2012. 

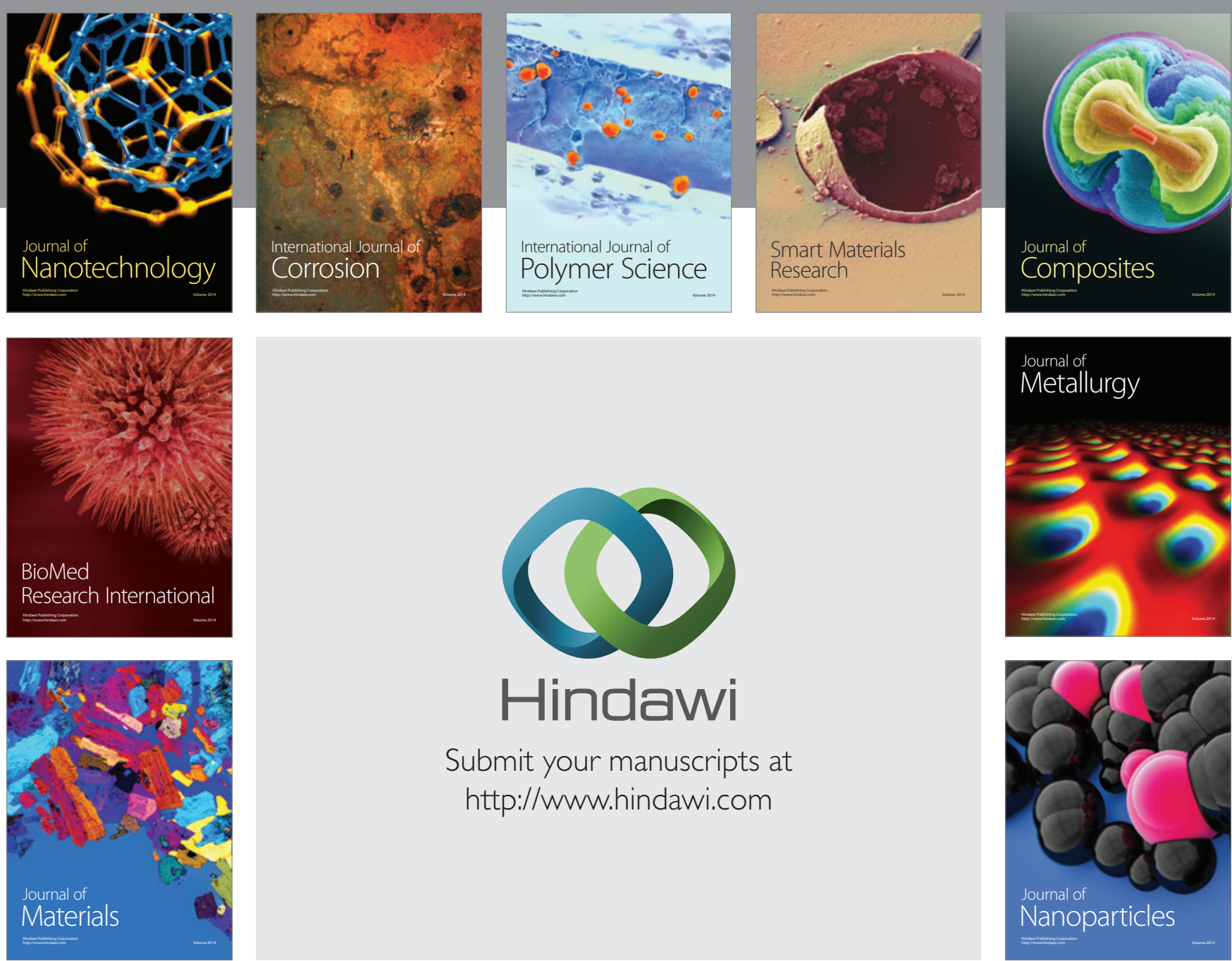

\section{Hindawi}

Submit your manuscripts at

http://www.hindawi.com

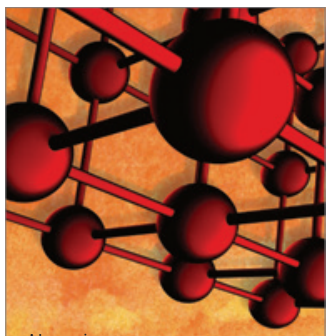

Materials Science and Engineering
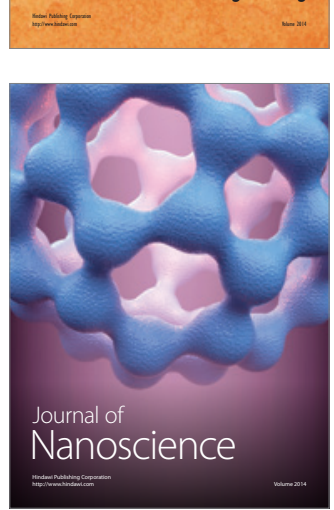
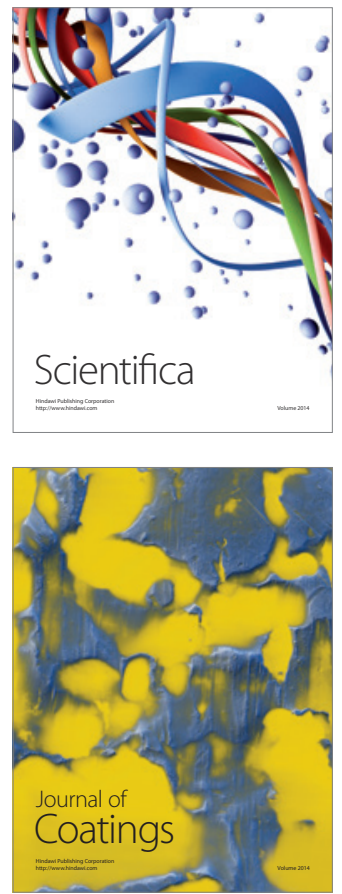
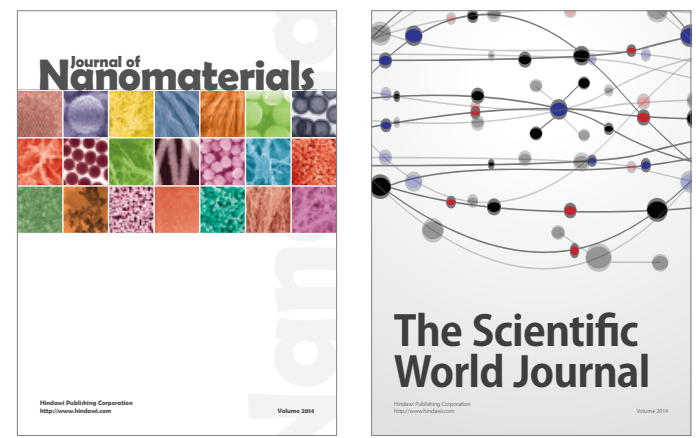

The Scientific World Journal
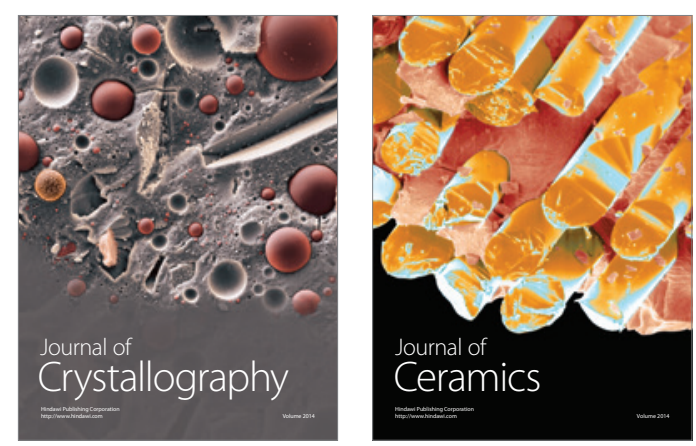
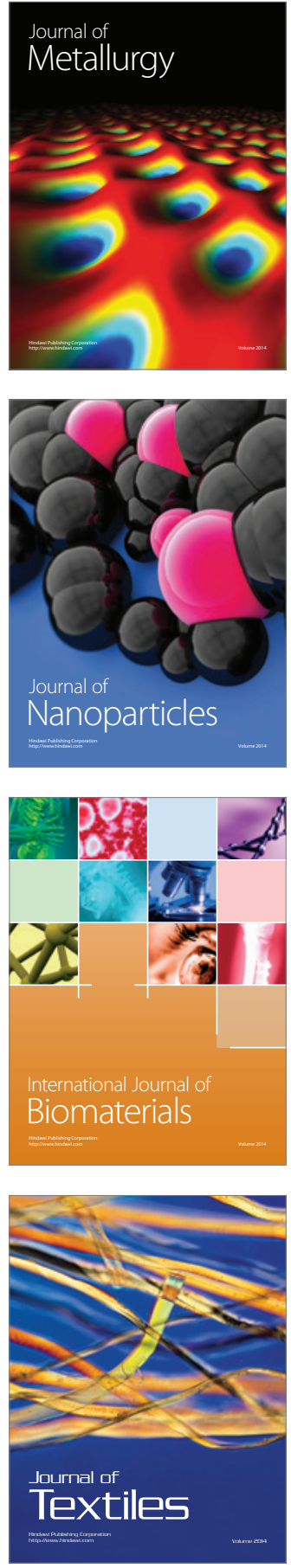